\title{
APROPRIAÇÕES E USOS DAS HISTÓRIAS EM QUADRINHOS NA LITERATURA DE CIÊNCIA DA INFORMAÇÃO
}

\author{
APROPIACIÓNES Y USOS DE HISTORIAS DE \\ COMICS EN LA LITERATURA EN CIENCIA DE LA \\ INFORMACIÓN
}

\author{
Valdir José Morigi* \\ Luis Fernando Herbert Massoni** \\ Thainá Ribeiro Loureiro***
}

\begin{abstract}
RESUMO
Introdução: O presente artigo realiza o mapeamento bibliográfico nos estudos da Ciência da Informação, para demonstrar o desenvolvimento das Histórias em Quadrinhos nesta área.

Objetivo: Mapear os estudos sobre Histórias em Quadrinhos realizados na Ciência da Informação, mostrando os seus usos e as apropriações no processo de disseminação dos resultados coletados nesta pesquisa.

Metodologia: Pesquisa bibliográfica com abordagem qualitativa-quantitativa.

Resultados: As Histórias em Quadrinhos são tema de pesquisa na Ciência na Informação sob a perspectiva da disseminação e interpretação da informação. O seu uso auxilia no aprendizado dos usuários e os estudiosos evidenciam seus benefícios. Os estudos destacam que as Histórias em Quadrinhos propiciam um esforço mental, pois os recursos visuais também permitem a aprendizagem. Os estudos também demonstraram que elas podem ser utilizadas para a pesquisa, em que são salientados os conhecimentos adquiridos na leitura de quadrinhos, ou seja, o conhecimento sem fundamentação científica.

Conclusões: Conclui que alguns estudos da Ciência da Informação determinam com quais finalidades as Histórias em Quadrinhos são apropriadas por usuários.
\end{abstract}

Palavras-chave: Histórias em quadrinhos. Mapeamento bibliográfico. Ciência da informação.

*Doutor em Sociologia pela Universidade de São Paulo (USP). Professor da Universidade Federal do Rio Grande do Sul (UFRGS). E-mail: valdir.morigi@gmail.com **Mestrando do Programa de Pós-Graduação em Comunicação e Informação da Universidade Federal do Rio Grande do Sul (UFRGS). Bolsista CAPES. E-mail: luisfernandomassoni@gmail.com

${ }^{* * \star}$ Graduada em Biblioteconomia pela Universidade Federal do Rio Grande do Sul (UFRGS). E-mail: thainna.ribeiro@hotmail.com 


\section{INTRODUÇÃO}

As Histórias em Quadrinhos (HQs) são utilizadas para o incentivo à leitura e a formação de leitores, além de serem recomendadas pelos Parâmetros Curriculares Nacionais (PCNs) e reconhecidas como uma ferramenta de alfabetização (CARVALHO, 2012). Os quadrinhos podem favorecer também o desenvolvimento de pesquisas científicas, cujas fundamentações teóricas têm ressaltado a sua importância para a sociedade e servido de suporte a novas reflexões, principalmente nos campos da Educação, Ciência Cognitiva e Ciência da Informação $(\mathrm{Cl})$.

As HQs são destinadas ao entretenimento de todos os públicos e têm sido tema de pesquisa na $\mathrm{Cl}$, sobretudo na Biblioteconomia, devido a sua função informativa. Assim, torna-se útil analisar as HQs e identificar como elas são utilizadas em publicações da respectiva área. Através de uma busca na literatura, constatamos que a importância das HQs está associada aos objetivos de aprendizagem e entretenimento, pois potencializa o gosto pela leitura. Este estudo lança a seguinte indagação: Quais as apropriações e os usos sobre as histórias em quadrinhos nos estudos na Ciência da Informação?

O estudo mapeia as pesquisas sobre as HQs realizados na Ciência da Informação, destacando os seus usos e as apropriações no processo de disseminação dos resultados da pesquisa na área. Além disso, identifica os elementos que compõe a linguagem das $H Q s$, caracteriza as histórias em quadrinhos como fonte de informação e analisa como são abordados os estudos na $\mathrm{Cl}$ que utilizam as $\mathrm{HQs}$, com relação a perspectivas teóricas, objetivos e metodologias. Trata-se de um estudo quali-quantitativo, bibliográfico e com objetivo exploratório com base em consulta à Base de Dados Referenciais de Artigos de Periódicos em Ciência da Informação (BRAPCI), o Google Acadêmico, a Biblioteca Digital de Teses e Dissertações (BDTD), Library and Information Science Abstracts (LISA), E-Prints in Library \& Information Science (E-LIS), Banco de Teses e Dissertações e o Portal de 
Periódicos da Coordenação de Aperfeiçoamento de Pessoal de Nível Superior (CAPES).

Como objeto de pesquisa da $\mathrm{Cl}$, os pesquisadores têm feito uso das HQs de forma a explorar o seu potencial, bem como seus recursos, com a finalidade de promover a aprendizagem e o lazer. Nesse sentido, as pesquisas científicas servem de suporte a novas "descobertas" sobre as apropriações e os usos que as HQs podem propiciar a seus usuários. Assim, esta pesquisa aponta a diversidade de temas, na área da $\mathrm{Cl}$, que as HQs oportunizam para auxiliar os diferentes interesses e cooperar na construção de valores que fortaleçam a cidadania.

\section{HISTÓRIAS EM QUADRINHOS: ENTRETENIMENTO, LINGUAGEM E FONTE DE INFORMAÇÃO}

Através de estudos científicos relativos à interpretação e disseminação da informação, as $H Q$ s vêm demonstrando seus benefícios para a população. Embora alguns as considerem prejudiciais, pesquisadores na área de $\mathrm{Cl}$ reforçam suas utilidades à sociedade, sobretudo ao público infantil: "As primeiras lembranças da infância, narradas em um discurso repleto de adjetivos afetivos, denotam a emoção do contato com as primeiras letras no lar como um verdadeiro presente." (BARI; VERGUEIRO, 2007, p. 19). Observa-se que, para muitos leitores, as $\mathrm{HQs}$ propiciam a iniciação da leitura e uma mistura de sentimentos inexplicáveis na infância, período marcado pela busca de novidades. As HQs se aproximam da linguagem oral, uma vez que o leitor pode "interagir" com a história, imaginando-a em seus pensamentos. Isso se confirma nas palavras de Eguti (2001 apud MARINHO, 2004), ao mencionar que as histórias em quadrinhos têm como objetivo principal a narração de fatos procurando reproduzir uma conversação natural, na qual as personagens interagem face a face, expressando-se por palavras e expressões faciais e corporais.

A origem dos quadrinhos vincula-se às pinturas rupestres na antiguidade que, por meio de uma sequência de imagens, exibiam 0 
cotidiano dos homens pré-históricos. Atualmente denominada de arte sequencial, era usada na Idade Média pela Igreja, para expor os episódios da vida dos homens santos em imagens (SILVA, 2011). Os registros históricos, assim, manifestavam o cotidiano da sociedade, como informações sobre o trabalho, colheita e caça na antiguidade.

O objetivo das HQs é buscar a compreensão dos leitores, através de recursos textuais e visuais. Concordamos com Becker e Grosch (2008, p. 37), quando relatam que "[...] o número ilimitado de fontes de informação disponibilizado atualmente faz com que surjam barreiras na [...] apropriação da leitura." Assim, é necessário explicar, primeiramente, como as linguagens visuais e textuais possibilitam a apropriação da leitura de HQs.

Observamos a facilidade com a qual são compreendidas as HQs pela forma como se tornam interessantes a quem as lê pela primeira vez. Conforme Santos e Ganzarolli (2011, p. 67), as HQs "[...] apresentam uma grande facilidade para que as crianças, em fase de alfabetização e início de escolarização, se interessem pela leitura e com ela se estimulem." A linguagem visual, aliada à textual, pode propiciar esse estímulo e promover a leitura, embora as HQs caracterizem-se pela linguagem coloquial, contrária à norma culta. De acordo com Paz (2015), as HQs foram consolidando uma reputação de leitura rasa e isso pode ser um dos motivos pelos quais não são totalmente garantia de aprendizagem para algumas pessoas. Para Santos e Ganzarolli (2011), apesar do baixo custo e da facilidade de encontrar HQs, pais e educadores "desconfiavam" deste tipo de leitura. A assimilação delas, geralmente, é facilitada por meio de seus recursos, tornando a leitura agradável e compreensível.

Os quadrinhos permitem a livre criação artística, uma vez que possibilitam ao autor desenvolver o roteiro, bem como a identidade visual. Dessa maneira, há HQs tradicionais, onde a ordem dos quadros facilita a compreensão da história, e aquelas com configuração diferente das tradicionais, como expõe Santos e Vergueiro (2012, p. 85): 
[...] os quadrinhos publicados em revistas, álbuns ou livros ocupam um espaço maior (de uma a centenas de páginas) e apresentam uma narrativa mais complexa. A leitura de uma página de quadrinhos também é um exercício de percepção mais apurada - embora boa parte das histórias apresente uma estrutura mais tradicional, em que um quadrinho segue o outro horizontalmente e de cima para baixo - há histórias que são diagramadas de maneira diferente, forçando o leitor a descobrir a sequência certa de imagens e textos.

A leitura de quadrinhos, consequentemente, pode não só facilitar a leitura, como também estimular a interpretação, fazendo com que o leitor identifique a ordem das vinhetas e a sequência da história. Há distintos formatos de quadrinhos (fanzines, tirinhas, graphic novels), publicações que podem influenciar os leitores, causando-os sentimentos diferentes, por exemplo, ao concluir a leitura de uma tirinha. Santos e Vergueiro (2012) afirmam que as tiras de quadrinhos exploram o gênero humorístico, onde apresentam uma situação inicial e uma reversão das expectativas do leitor (textuais ou visuais), gerando o efeito cômico. Cabe ressaltar que as tirinhas apresentam, em sua maioria, recursos visuais, pois as histórias são curtas, publicadas em 3 ou 4 vinhetas.

Embora possibilitem a assimilação da informação, caracterizar as HQs como fonte de informação convencional é uma tarefa difícil, uma vez que existem poucos estudos sobre o tema, mas tentaremos comparar as histórias em quadrinhos com a função da televisão. Segundo Bretas (2005), a influência televisiva pode acontecer por intermédio da função informativa, formativa e de entretenimento: a informativa objetiva a busca e disseminação de notícias relevantes; a formativa promove a educação do público. Já o entretenimento compreende o lazer proporcionado por esses meios de comunicação. Observamos que essas funções também são desempenhadas pelos quadrinhos, pois podem capacitar o público através de informações úteis e, ao mesmo tempo, promover o entretenimento.

As HQs se caracterizam como fonte empírica, isso é, a informação pode ser resultado de experiências, como a leitura constante 
de quadrinhos na infância, desenvolvendo a compreensão de recursos linguísticos não antes vistos pela criança, por exemplo. $O$ empirismo pode ser caracterizado como fonte de pesquisa também e, nesse sentido, acreditamos que esse conhecimento tem facilitado determinados estudos sobre HQs, como as percepções apontadas no estudo de Bari e Vergueiro (2007, p. 23), pelo qual são classificadas como fonte de informação: "[...] ampliou-se o reconhecimento do valor da leitura das histórias em quadrinhos, que se vem constituindo em fontes de informação e conhecimento, progressivamente inseridas em práticas pedagógicas no ensino básico e fundamental."

Como fonte de informação e conhecimento, as HQs também estão inseridas no ensino superior, sobretudo para desmitificar as barreiras sociais enfrentadas por seus usuários. Conforme Vergueiro (1998), os entraves dominaram durante muito tempo e não se pode afirmar que tenham realmente deixado de existir. Ainda acontece de proibirem a leitura desse tipo de material, mas há estudos científicos que demonstram o potencial das HQs, seja como leitura ou fonte de pesquisa:

Felizmente, o interesse crescente dos estudiosos pelas histórias em quadrinhos, principalmente a partir da década de 60 , bem como a realização de pesquisas sérias e bem alicerçadas, acabaram demonstrando que boa parte dessas barreiras não possuía qualquer fundamento científico, consistindo em preconceitos totalmente desprovidos de comprovação (VERGUEIRO, 1998, p. 131-132).

O interesse dos pesquisadores pelas HQs causa a possibilidade de inserção destas em bibliotecas universitárias e disciplinas. Assim, várias iniciativas têm sido criadas para fomentar a sua utilização como fonte de informação: o Observatório de Histórias em Quadrinhos, grupo de pesquisa da Escola de Comunicação da Universidade de São Paulo (USP), promove palestras, reuniões e eventos, como as Jornadas Internacionais de Histórias em Quadrinhos, cuja proposta é servir de 
ponto focal para as pesquisas sobre HQs produzidas em diferentes regiões do país e também no exterior. Além disso, o Brasil foi o primeiro país a inserir uma disciplina sobre as HQs em um curso de graduação e a organizar um curso de especialização sobre este tema (VERGUEIRO, 1998). Nesse sentido, considera-se que as HQs facilitam o uso eficiente da informação, como Campello e Caldeira (2005) expõem, e contribuem para a apropriação do conhecimento, de forma que este promova a utilização das $\mathrm{HQs}$ como fonte de informação, bem como as atividades pelas quais os quadrinhos são objeto de estudo.

Estamos expostos diariamente a um grande volume de informações, disseminadas em distintos tipos de mídias - televisão, rádio, jornal ou revista. Concordamos com Vergueiro (2005), quando evidencia os quadrinhos como produto de expressiva influência para a sociedade, assim como os veículos de comunicação citados acima. Essa influência é causada pelo poder que os meios de comunicação de massa possuem na sociedade. As HQs também adquiriram esse prestígio, embora mais tarde que os meios tradicionais de comunicação, através de sua linguagem textual e visual, característica pelas quais autores como Assis (2011) as consideram como gênero: na $H Q$, esse contexto é fruto da dicotomia verbal/não verbal, na qual tanto os desenhos como as palavras são necessárias ao entendimento da história.

Embora as HQs se assemelhem a obras literárias, pois de acordo com Santos e Vergueiro (2012), compartilham elementos narrativos típicos do texto literário e se tem prestado para a adaptação de contos ou de romances, há, ainda, divergências quanto ao gênero que as HQs representam, uma vez que alguns pesquisadores consideram narrativo, enquanto que outros discursivo. Assim sendo, atribuir um único gênero aos quadrinhos é uma tarefa complexa, pois podemos caracterizá-los de distintas maneiras, como destaca os Parâmetros Curriculares Nacionais: 
Os gêneros existem em número quase ilimitado, variando em função da época (epopéia, cartoon), das culturas (haikai, cordel) das finalidades sociais (entreter, informar), de modo que, mesmo que a escola se impusesse a tarefa de tratar de todos, isso não seria possível. Portanto, é preciso priorizar os gêneros que merecerão abordagem mais aprofundada (BRASIL, 1998, p. 24).

Embora o gênero narrativo esteja vinculado a estes estilos, como destaca Vergueiro (1998), nossa proposta é compreender o gênero discursivo. Pode-se afirmar que os estudos científicos são disseminados para satisfazer as necessidades informacionais dos pesquisadores. Igualmente, os gêneros existem em função da necessidade humana de comunicação (ASSIS, 2011). Neste sentido, as HQs cumprem o objetivo de se comunicar com os seus leitores e, para tanto, faz-se necessário a comunicação, assim como a construção do gênero discursivo:

Na reflexão bakhtiniana, a noção de gênero discursivo reporta ao funcionamento da língua em práticas comunicativas, reais e concretas, construídas por sujeitos que interagem nas esferas das relações humanas e da comunicação. É, no interior dessas esferas, correspondentes às instâncias públicas e privadas do uso da linguagem, que se elaboram os gêneros discursivos, para responderem às necessidades interlocutivas dos sujeitos que nelas se inter-relacionam. (SILVA, 1999, p. 5).

A produção e disseminação são as atividades pelas quais os gêneros discursivos, através das trocas de comunicação entre os sujeitos, estabeleceram-se naturalmente nos quadrinhos (SILVA, 1999). Igualmente, as HQs têm sido aceitas pela sociedade, na medida em que esta tem consciência da sua importância social na satisfação das necessidades do ser humano, utilizando a imagem como elemento de comunicação de massa (VERGUEIRO, 1998). Portanto, a imagem pode ser mais influente do que o próprio texto, justamente porque atua como mediadora no processo de comunicação entre os usuários de quadrinhos. 


\section{HISTÓRIAS EM QUADRINHOS NOS ESTUDOS DE CIÊNCIA DA INFORMAÇÃO}

As HQs têm sido tema de estudos que privilegiam os processos de tratamento, disseminação e interpretação da informação, vertentes da literatura em Ciência da Informação. Através dessas três categorias, Freire (2006) sugeriu as suas respectivas linhas de pesquisa ${ }^{1}$, proposição que consideramos apropriada para identificar os temas específicos dos estudos de interpretação e disseminação dos quadrinhos na $\mathrm{Cl}$.

Pesquisamos em bases de dados como a BRAPCI, o Google Acadêmico, a BDTD, a LISA, a E-LIS, o Banco de Teses e Dissertações e o Portal de Periódicos da CAPES. Escolhemos estes sistemas de busca em função de sua relevância e relação com a Ciência da Informação. Os termos de busca empregados são "Ciência da Informação AND quadrinhos", à exceção do Portal da CAPES, em que as palavras-chave foram apenas quadrinhos. Delimitamos os estudos dos últimos sete anos (2008-2014), pois nesse período coletamos documentos suficientes para análise e utilização na presente pesquisa, compondo um corpus de 10 textos. Optou-se pela pesquisa de fontes cujos idiomas sejam em língua portuguesa, para facilitar a compreensão. Após a etapa de coleta, procedemos à análise dos dados relevantes, como descrito abaixo.

Os documentos foram consultados quanto a sua pertinência e clareza e a relação das $\mathrm{HQs}$ com a $\mathrm{Cl}$. Posteriormente, as 10 pesquisas selecionadas foram analisadas, com o objetivo de relacioná-las às categorias de comunicação da informação ou estudos da cognição, propostas por Freire (2006). Importante é ressaltar que excluímos do levantamento os estudos sobre recuperação da informação, pois não atendem aos objetivos desta pesquisa, embora também sejam

\footnotetext{
${ }^{1}$ Recuperação e comunicação da informação e estudos da cognição.
} 
importantes para o desenvolvimento da $\mathrm{Cl}$. Por fim, dos documentos coletados, cinco foram identificados à categoria de disseminação e cinco à interpretação da informação.

\subsection{Histórias em Quadrinhos e os Estudos de Disseminação}

Observamos, a partir da leitura de autores da Ciência da Informação, que as HQs podem auxiliar na aprendizagem, uma vez que se utilizam de linguagem verbal e visual. Como Neves (2007) reforça, a aprendizagem é um processo consciente de aquisição de informação, que gera conhecimento. Nesse sentido, analisaremos os estudos cujos propósitos são propiciar conhecimento, seja científico ou popular. Essas pesquisas, da área da $\mathrm{Cl}$, contribuem para a aquisição de informação e, também, disseminação de gibis e estudos científicos nesta área.

Os estudos são unânimes: HQs contribuem para a aprendizagem da leitura. Entretanto, têm abordado perspectivas teóricas distintas, quanto à maneira com a qual são formados leitores através da leitura de HQs: o estudo de Santos e Ganzarolli (2011) tem por objetivo conhecer os projetos em que as HQs são utilizadas para promover e incentivar a leitura nas bibliotecas e escolas. Normalmente, os quadrinhos são considerados publicações exclusivas do segmento infanto-juvenil, premissa fundamentada na certeza de que "[...] a leitura deve ser inserida, desde muito cedo, na vida das crianças [...]" e que "[...] as $\mathrm{HQ}$ apresentam uma grande facilidade para que as crianças, em fase de alfabetização e início de escolarização, se interessem pela leitura e com ela se estimulem [...]" (SANTOS; GANZAROLLI, 2011, p. 67).

Toda gibiteca deveria estabelecer um ou mais objetivos para que o seu planejamento seja concretizado, pois, principalmente através dos bibliotecários, as gibitecas podem inovar. É necessário estimar a quantidade e a qualidade dos projetos em que os bibliotecários são mediadores: o estudo constatou que apenas a Gibiteca Leitura Prazer realiza efetivamente a promoção da leitura de quadrinhos, através de atividades como o concurso em que os melhores desenhos são 
publicados em um gibi.

Igualmente essencial é a participação do professor na promoção da leitura. De acordo com Santos e Ganzarolli (2011), ele pode utilizar os quadrinhos de distintas maneiras, como um valioso recurso de fomento à leitura e um eficiente auxiliar no ensino em diversas disciplinas e atividades. Assim, as autoras elegeram o Projeto G como mais adequado à mediação da leitura, já que "[...] trabalha de forma positiva a autoestima de professores e alunos, mostrando que mesmo escolas com poucos recursos podem oferecer grandes oportunidades [...]" (SANTOS; GANZAROLLI, 2011, p. 72). A mediação da leitura pode ser realizada pela parceria de professores e bibliotecários e as autoras (SANTOS; GANZAROLLI, 2011, p. 73) consideram que "[...] um trabalho interdisciplinar entre professores e bibliotecários pode gerar resultados com muito mais qualidade." Dessa maneira, foi possível constatar no estudo que o Projeto $\mathrm{H}$ - Gibiteca Leitura Prazer - realiza um trabalho em conjunto, pois "[...] se integra ao processo pedagógico e participa de uma proposta de aprendizado interdisciplinar, permitindo modificar a situação atual, idade em que muitas crianças e jovens leem pouco e geralmente não entendem o que estão lendo." (SANTOS; GANZAROLLI, 2011, p. 73). Existem projetos que efetivamente atuam no processo de leitura e apropriação das HQs.

O fomento à leitura de HQs também é destaque no estudo de Silva Júnior, Pereira e Soares (2013), para os quais as relações entre o cinema e a leitura estão em constante desenvolvimento, pois se interligam à medida em que livros e gibis dão origem a filmes e, inversamente, filmes inspiram os roteiristas de quadrinhos. Assim, a pesquisa tem como problema a seguinte indagação: o grande sucesso dos filmes da Marvel no cenário globalizado da sociedade brasileira tem influenciado e contribuído para o aprimoramento e o incentivo da leitura de HQ? Os objetivos que norteiam esta pesquisa são verificar se os usuários de uma gibiteca, após assistirem a um filme da Marvel, sentiram-se estimulados e mais interessados na leitura de HQs, livros e 
revistas.

Dessa forma, 20 sujeitos que já haviam assistido algum filme de super-heróis foram consultados quanto à influência que o cinema pode ter em relação aos usuários da gibiteca, sobretudo quanto à promoção da leitura. Assim, 70\% deles respondeu que o cinema exerce muita influência para a leitura, enquanto que 30\% acreditam serem influenciados de forma mediana. Os autores necessitaram saber também se assistir aos filmes da Marvel pode promover a leitura de HQs com o gênero de super-heróis: de forma massiva, 95\% dos entrevistados afirmaram que leem as histórias em quadrinhos pois sentem-se interessados em continuar a explorar aquilo que o próprio filme não exibiu, já que, geralmente, seu roteiro é diferente do enredo das HQs. Igualmente, as personagens podem influenciar a prática da leitura, uma vez que a pesquisa apontou a importância dos super-heróis para os usuários da gibiteca. Os autores consideram que a pesquisa atingiu os objetivos propostos, pois, a exemplo dos gibis, os filmes da Marvel podem promover também a leitura de quadrinhos.

A promoção da leitura de HQs é abordada também por Santos e Vergueiro (2012), cujo artigo destaca mais aplicações dos quadrinhos no processo de aprendizagem. Concordamos com os autores, quando ressaltam que as HQs não são específicas de apenas uma área de ensino. Assim, é possível disseminar informação jurídica, por exemplo.

Devido à visibilidade da $\mathrm{HQ}$, Maurício de Souza publicou diversas cartilhas educativas da Turma da Mônica que visam informar os leitores, por exemplo, sobre os direitos humanos, sendo essas cartilhas o objeto de estudo de Silva e Silva (2012). Trata-se de um estudo que objetiva analisar o potencial dessas ao acesso à informação. De acordo com os autores, o Estatuto da Criança e do Adolescente, de autoria de Maurício, apresenta linguagem simplificada, uma vez que os leitores infantis compreendem sua definição, bem como as garantias de todo cidadão. Através da cartilha "Os Direitos Humanos", O Menino Maluquinho também expõe os direitos da sociedade. Entretanto, a linguagem visual 
destaca-se, para divulgar o artigo $5^{\circ}$ da Constituição Federal. O Código de Defesa do Consumidor, terceira cartilha analisada, também apresenta recursos visuais, os quais visam a compreensão das crianças sobre a respectiva legislação, como balões e excesso de cores. De acordo com os autores (SILVA; SILVA, 2012, p. 179), "[...] este simples, mas rico exemplo, faz com que o público infantil compreenda o conceito de consumidor e consiga até a orientar seus pais."

Acordamos com eles quando expõem a necessidade de um estudo para verificar a recepção dessas cartilhas pelo público infantil, no intuito de comprovar o seu potencial para o acesso à informação. Supõe-se, assim, que as cartilhas representam o processo de disseminação da informação na área da $\mathrm{Cl}$, pois empregam uma linguagem acessível ao público, todavia propícia para estudos nesta área.

O mapeamento bibliográfico de HQs na área da Biblioteconomia e Cl também foi abordado por Oliveira e Nóbrega (2013): os autores realizaram um estudo cuja justificativa é buscar subsídios que comprovem a escassez da pesquisa sobre HQs na área. Trata-se de uma pesquisa em que foram realizadas duas buscas na Plataforma Lattes: a primeira com os termos Biblioteconomia e Quadrinhos; a segunda com os termos Ciência da Informação e Quadrinhos. Foram obtidos, respectivamente, 87 e 99 resultados, com as seguintes temáticas:

a) Temas na Biblioteconomia: incentivo à leitura, biblioteca pública, cultura e semiótica;

b) Temas na $\mathrm{Cl}$ : identidade e dinamização de coleções;

c) Temas em ambas: formação de leitores, leitura (linguagem/processo), processamento técnico, estudos de usuários/leitores, fontes de informação, memória, educação, gibitecas, mediação, análise do discurso. 
Os resultados apontaram a semelhança das temáticas localizadas na Biblioteconomia e Cl. Além disso, Oliveira e Nóbrega (2013) explicam que o estudo sobre quadrinhos é incipiente, pois muitos pesquisadores não as utilizam como objeto de pesquisa, mas sim como possibilidade de estudar um material diferente, que não sejam os livros e os periódicos.

O estudo de Pigozzi (2013) efetivamente utiliza as HQs como objeto de pesquisa. $O$ autor realiza um estudo com dois quadrinhos com o intuito de compreender a questão do autoritarismo na sociedade. Para tanto, busca aprofundar a análise das HQs de um roteirista, através do impacto que sua produção teve em relação ao mercado dos quadrinhos. Além disso, são consultadas as bibliografias que enfocam as diferentes perspectivas sobre as HQs como meio de comunicação de massa e recurso informacional.

Como recurso para comunicação em massa, segundo o autor (PIGOZZI, 2013, p. 15), "[...] as histórias em quadrinhos desempenham o papel de levar a arte e diversas outras formas de expressão cultural a um número maior de pessoas, as quais possuem diversas faixas etárias e também diferentes níveis sócio-econômicos." O autor elencou as obras cujos contextos são os regimes totalitários e, de acordo com ele, embora o número de publicações seja significativo, as histórias em quadrinhos sofreram a resistência devido a dificuldades de produção da época, bem como a repressão policial exercida contra os quadrinistas e sua produção artística.

$\mathrm{O}$ autor identifica, na primeira $\mathrm{HQ}$ analisada, a história da guerra contra o comunismo e a defesa dos grupos sociais oprimidos pelas situações de trabalho insalubres e salários miseráveis. Dessa maneira, o quadrinho defende a necessidade de luta em favor da liberdade de escolha, pensamento, opinião, expressão e imprensa, tendo em vista sua anulação em sistemas totalitários e sociedades estruturalmente desiguais (PIGOZZI, 2013). A segunda história retrata a ameaça da guerra nuclear entre os Estados Unidos e a extinta União Soviética, 
através de alegorias, segundo o autor. A HQ nos leva a refletir sobre os Direitos Humanos e a influência do regime autoritário (PIGOZZI, 2013). Verificamos, portanto, a importância dos quadrinhos também como recurso para a construção de valores e cidadania, ou seja, as HQs cumprem o papel de fazer com que o usuário reflita durante a leitura, de modo a interpretar e conhecer seus enredos, os quais podem ser inspirados em histórias verídicas.

\subsection{Histórias em Quadrinhos e os Estudos de Interpretação}

A construção de conhecimento necessita de disseminação da informação através dos meios informativos e científicos. Para tanto, é necessário adequar a linguagem das fontes de informação, de modo que os usuários saibam interpretar corretamente. Nesse sentido, os estudos sobre HQs auxiliam os leitores de diversas maneiras, como os exercícios de interpretação que elas podem propiciar.

Ramos e Dumont (2008, p. 2) consideram que, "[...] ao se tornar um leitor, o sujeito tem a possibilidade de compreender a sociedade valendo-se de um maior alcance intelectual e ampliando sua visão do mundo." Os autores analisaram os usuários de HQs de super-heróis, entendendo que estes se espelham nessas personagens. $O$ estudo objetiva investigar como as HQs proporcionam que os usuários compreendam e reflitam sobre a sociedade e de que maneira utilizam o conhecimento obtido com a leitura. Para tanto, foi realizada uma pesquisa de campo com 20 leitores de HQs com enredo de superheróis. Os autores identificaram a forma como os leitores se classificam em relação às $\mathrm{HQs}$, abrangendo categorias como leitores fanáticos, leitores eventuais, pesquisadores de HQs, dentre outras.

Além disso, os leitores também foram consultados quanto ao emprego dos conhecimentos obtidos com a leitura de HQs, como a identificação com determinado herói ou vilão, tendo em vista que pode proporcionar uma forma de acesso ao conhecimento e, também, contrastar, refutar ou até mesmo concordar com um ponto de vista já 
estabelecido (RAMOS; DUMONT, 1998). Assim, os super-heróis são admirados por usuários de HQs devido a diferentes características, tais como autocontrole, conhecimento dos resultados de suas ações, senso de responsabilidade, capacidade de persuasão e perspicácia. É interessante a presença de personagens que, embora tidos como vilões, não são do "mal", pois apenas desejam alcançar seus objetivos, sendo que sua criação e histórico justificam suas ações.

Pode-se afirmar que as HQs com enredo de super-heróis exercem influência nos seus leitores, tanto na vida profissional como na vida pessoal. Para Ramos e Dumont (1998), a pesquisa indicou que estes extraem da leitura os conceitos e as práticas apontadas pelos heróis e, a partir disso, começam a refletir sobre o que foi lido.

Os leitores podem ter uma relação afetiva com os quadrinhos, mas Bari (2008) acredita que ela não se manifesta apenas nas possibilidades de fruição e felicidade, como nas oportunidades concretas de empregabilidade e na melhoria da qualidade de vida. Nesse sentido, a autora define o problema de sua pesquisa através da relação entre a participação social e o ingresso na cultura letrada, pois acredita que exista uma ligação entre o pleno usufruto da produção material e cultural da sociedade e o desenvolvimento de habilidades, competências, hábitos e gostos no âmbito da leitura. O estudo de Bari (2008) objetiva verificar a efetividade das HQs na formação de leitores, no contexto da Biblioteconomia e da Educação.

O estudo aponta, através de pesquisas de campo e investigações, a validade cultural na leitura de quadrinhos. Entretanto, esta "[...] somente será possível por meio do amadurecimento internacional de políticas públicas que considerem as histórias em quadrinhos como bens culturais relevantes à formação do leitor, com sua consequente inserção nos espaços públicos e ambientes educativos voltados a leitura." (BARI, 2008, p. 224). Assim, a autora destaca os programas que visam à formação do leitor: PROLER, Plano Nacional do Livro e da Leitura (PNLL), Programa Nacional do Livro Didático (PNLD), 
Programa Nacional de Biblioteca da Escola (PNBE), dentre outras iniciativas que possibilitam a evolução das práticas de leitura. No entanto, ela salienta que o Brasil ainda permanece em situação precária e, em função disso, torna-se necessária a atuação do bibliotecário para o fomento à leitura. Nesse sentido, a formação desses profissionais deve priorizar a adaptação das habilidades e competências, bem como bastante autodidatismo (BARI, 2008).

A autora evidencia que os brasileiros têm se apropriado das HQs e seus conteúdos. No Brasil, já existem cursos superiores com ênfase em HQs, como a Produção de Cartoon, Charge e Histórias em Quadrinhos, vinculada à Universidade Estácio de Sá, do Rio de Janeiro, enquanto que os demais estados têm inserido disciplinas sobre HQs no ensino superior, embora enfatizem apenas aspectos históricos ou técnicas de leitura (BARI, 2008).

$\mathrm{Na}$ área da Educação e da Ciência da Informação, o estudo de Santos e Vergueiro (2012, p. 84) "[...] tem como objetivos apresentar reflexões sobre a utilização de histórias em quadrinhos na educação e indicar algumas práticas pedagógicas que aproveitem melhor o potencial dos quadrinhos." Os autores confirmam que, através das HQs, a ciência pode ser melhor aproveitada em sala de aula, pois há HQs que abordam temas referentes à ciência.

Os autores reforçam que, independente dos tipos e aplicações utilizados, empreender atividades práticas a partir dos quadrinhos torna as aulas mais dinâmicas e o aprendizado mais prazeroso. Para tanto, é necessário separar as publicações, de acordo com suas apropriações ou as informações relevantes em seus conteúdos (SANTOS; VERGUEIRO, 2012). E, por fim, eles lembram que a leitura de quadrinhos é complexa e não deve se restringir ao texto ou ao enredo, justamente porque possibilita a construção de sentidos.

A formação do leitor pode depender da linguagem utilizada nas HQs, segundo Costa e Orrico (2009), que realizaram um estudo voltado a sua compreensão, com o objetivo de entender o processo de 
construção de sentido, uma vez que pode facilitar a disseminação de informação e o processo de leitura das HQs. Nesse sentido, o estudo define a linguagem quadrinística:

A linguagem das histórias em quadrinhos caracteriza-se de distintas maneiras, das mais simples às mais complexas. Entretanto, no momento em que o leitor tem contato com as HQs, chama sua atenção a união da linguagem imagética - reunindo as noções de perspectiva, simetria, hachuras, pinceladas, tonalidades, contornos e cores - e a textual abrangendo a gramática, a sintaxe, sistemas morfológicos e outros (COSTA; ORRICO, 2009).

Entretanto, os autores salientam que, provavelmente, a imagem se sobressaia em relação ao texto. A união dos elementos imagéticos e visuais pode submeter o leitor a uma impressão equivocada, por exemplo, quando o interlocutor descreve um acontecimento, mas a imagem exibe outro, ou seja, dois episódios construídos concomitantemente por linguagens distintas, na mesma narrativa (COSTA; ORRICO, 2009). Os autores ressaltam ainda que a relação texto-imagem pode causar um fator de redundância à leitura do usuário.

O texto também sofre modificações, de acordo com o que desejam comunicar aos leitores. As palavras sofreram um tratamento plástico quanto ao tamanho, à cor, à forma e à espessura, tornando-se elementos importantes para o texto. Mas o que diferencia as HQs das outras obras, provavelmente, é a arte sequencial: a sequência de imagens define as HQs como as conhecemos, pois a leitura de uma narrativa, geralmente, ocorre no sentido da esquerda para direita e de cima para baixo dentro do limite de uma página (COSTA; ORRICO, 2009).

Como vimos, Costa e Orrico (2009) indicam as particularidades da linguagem quadrinística e salientam que a produção de sentido consiste na leitura do "todo articulado": uma página ou um quadrinho seriam apenas um fragmento desse "todo articulado", exceto quando a história possui início, meio e fim em apenas uma página, pois, nesse 
caso, a página não seria um fragmento, mas a história em sua completude. Concordamos com os autores quando destacam a complexidade dos quadrinhos, pois o usuário necessita conhecer os enunciados das HQs, bem como o gênero discursivo, para poder assimilar e produzir informação (COSTA; ORRICO, 2009).

As HQs, mais do que proporcionar exercícios de interpretação, formam leitores e pensadores e, para Bari (2012), amadurecem a relação emocional entre a leitura e seus leitores, os quais apreciam todos os tipos de literatura, da popular à erudita. Nesse sentido, o estudo da autora visa a formação do leitor, bem como os espaços de leitura em que estes podem usufruir dos quadrinhos.

As gibitecas são acervos especialmente desenvolvidos para os leitores de HQs e Bari (2012) considera que elas têm o potencial para servir à faixa etária infanto-juvenil, através da alfabetização e formação de hábitos e gostos específicos de leitura, pois estimulam estes leitores a produzir e trocar entre seus semelhantes as suas próprias histórias. A autora cita como se forma uma gibiteca, pois é necessário oferecer uma estrutura condizente com o público frequentador do local. Para o segmento infantil, a decoração deve ser convidativa, com tapetes e almofadas ilustrando o espaço. Já para o público adulto são necessárias mesas, poltronas e pranchas para leitura dos álbuns (BARI, 2012). A autora reforça que a gestão do acervo possibilita aos usuários habituarse com a gibiteca e, também, com a prática de leitura.

A gibiteca é um espaço cultural, uma vez que permite a realização de atividades cujas finalidades são promover o saber e o entretenimento. As animações infantis são um exemplo: podem se valer de inúmeros objetos, mas devem ter o momento da leitura direta no papel como o mais importante do evento, porque as crianças necessitam saber qual a fonte de tanto entretenimento (BARI, 2012). Por fim, concordamos com a autora quando afirma que devemos juntar nossos esforços à construção de uma gibiteca inovadora, convidativa, informativa, criativa e passível de usufruir das nossas aliadas, as HQs. 


\section{CONSIDERAÇÕES FINAIS}

Identificamos as pesquisas sobre as $\mathrm{HQs}$ na $\mathrm{Cl}$, destacando suas apropriações e usos na área. O seu uso auxilia no aprendizado dos usuários e os estudiosos evidenciam os seus benefícios, principalmente àqueles que ainda os consideram vilões da leitura e do letramento. Também destacam que o cinema tem conquistado o público, influenciando o espectador a usufruir das HQs, satisfazendo seu interesse pela história e que são necessários mediadores para salientar os benefícios das HQs à sociedade. Nesse sentido, professores e bibliotecários podem atuar juntos, em favor dos leitores, experientes e iniciantes. Os estudos destacam que a HQ propicia um esforço mental, no intuito do leitor descobrir a ordem das vinhetas, quando a diagramação dos quadros não é sequencial, por exemplo, pois os recursos visuais também permitem a aprendizagem. Essas são algumas das razões apontadas pelos pesquisadores a respeito da importância das HQs para a sociedade.

Caracterizamos as HQs como fonte de informação e os estudos demonstraram que, embora não sejam fonte convencional, podem ser utilizadas para a pesquisa, como a empírica, em que são salientados os conhecimentos adquiridos na leitura de quadrinhos, ou seja, o conhecimento sem fundamentação científica. Nesse contexto, os leitores destacam a influência dos super-heróis, uma vez que essas personagens retratam os valores dos quais eles compartilham. Constatamos que os quadrinhos têm sido utilizados como fonte de informação, capacitando o público através de informações úteis e promovendo o entretenimento.

Muitos usuários de HQs desconhecem seus benefícios, embora apreciem a leitura de um gibi. Dessa maneira, o entretenimento pode ser o principal incentivo para que os quadrinhos despertem o interesse de leitores. Em relação aos estilos de HQs, existem variadas opções de leitura, a qual pode estimular o usuário a migrar para as obras literárias, 
Valdir José Morigi; Luis Fernando Herbert Massoni; Thainá Ribeiro Loureiro Apropriações e usos das histórias em quadrinhos na literatura de Ciência da Informação

da mesma maneira em que constatamos a influência do cinema para a leitura, de acordo com os resultados dos estudos.

Em algumas pesquisas, verificamos a necessidade de averiguar, principalmente, com quais finalidades os usuários utilizam os quadrinhos, ou seja, determinar as suas apropriações através das respostas dos usuários. Cabe ressaltar que alguns estudos concluíram ser essencial obter estes dados, uma vez que ratificariam 0 conhecimento dos pesquisadores e, também, o empírico. Ainda assim, entendemos a importância das HQs, seja como fonte de informação ou entretenimento, bem como dos profissionais que as consideram valiosos recursos para a efetivação da leitura, da aprendizagem e da transmissão do conhecimento.

\section{REFERÊNCIAS}

ASSIS, Lúcia Maria. Histórias em quadrinhos: linguagem, memória e ensino. In: SILEL, 2., 2011, Uberlândia. Anais... Uberlândia: EDUFU, 2011.

BARI, Valéria Aparecida. Leitura escolar e histórias em quadrinhos: fruição intelectual, criatividade e formação de gostos de leitores. Nona Arte, São Paulo, v. 1, n. 2, p. 25-33, 2012.

BARI, Valéria Aparecida. O potencial das histórias em quadrinhos na formação de leitores: busca de um contraponto entre os panoramas culturais brasileiro e europeu. 2008. Tese (Doutorado em Ciência da Informação) - Escola de Comunicações e Artes, Universidade de São Paulo, São Paulo, 2008.

BARI, Valéria Aparecida; VERGUEIRO, Waldomiro. As histórias em quadrinhos para a formação de leitores ecléticos: algumas reflexões com base em depoimentos de universitários. Comunicação \& Educação, São Paulo, v. 12, n. 1, p. 15-24, jan./abr. 2007.

BECKER, Caroline da Rosa Ferreira; GROSCH, Maria Selma. A formação do leitor através das bibliotecas: o letramento e a Ciência da informação como pressupostos. Revista Brasileira de Biblioteconomia e Documentação, São Paulo, v. 4, n. 1, p. 35-45, jan./jun. 2008. 
Valdir José Morigi; Luis Fernando Herbert Massoni; Thainá Ribeiro Loureiro Apropriações e usos das histórias em quadrinhos na literatura de Ciência da Informação

BRASIL. Parâmetros curriculares nacionais: terceiro e quarto ciclos do ensino fundamental: língua portuguesa. Brasília: MEC, 1998.

BRETAS, Maria Beatriz Almeida S. Televisão. In: CAMPELLO, Bernadete Santos; CALDEIRA, Paulo da Terra. Introdução às fontes de informação. Belo Horizonte: Autêntica, 2005. p. 89-100.

CAMPELLO, Bernadete Santos; CALDEIRA, Paulo da Terra.

Introdução às fontes de informação. Belo Horizonte: Autêntica, 2005.

CARVALHO, Gisleine. O incrível poder das histórias em quadrinhos.

Educar Para Crescer, São Paulo, fev. 2012.

COSTA, Robson Santos; ORRICO, Evelyn Goyannes Dill. A construção de sentido na informação das histórias em quadrinhos. DataGramaZero, Rio de Janeiro, v. 10, n. 2, 2009.

FREIRE, Gustavo Henrique. Ciência da Informação: temática, histórias e fundamentos. Perspectivas em Ciência da Informação, Belo Horizonte, v. 11, n. 1, p. 6-19, jan./abr. 2006.

MARINHO, Elyssa Soares. Histórias em quadrinhos: a oralidade em sua construção. In: CONGRESSO NACIONAL DE LINGUÍSTICA E FILOLOGIA, 8., 2004, Rio de Janeiro. Anais... Rio de Janeiro: UERJ, 2004.

NEVES, Dulce Amélia Brito. Meta-aprendizagem e ciência da informação: uma reflexão sobre o ato de aprender a aprender.

Perspectivas em Ciência da Informação, Belo Horizonte, v. 12, n. 3, p. 116-128, set./dez. 2007.

OLIVEIRA, Maria Jaciara de Azeredo; NÓBREGA, Nanci Gonçalves.

Conhecer para mediar: investigação sobre as pesquisas com quadrinhos em biblioteconomia e ciência da informação. In: ENCONTRO

NACIONAL DE PESQUISA EM CIÊNCIA DA INFORMAÇÃO, 14., 2013, Florianópolis. Anais... Florianópolis: UFSC, 2013, p. 1-6.

PAZ, Liber. 10 centavos sobre quadrinhos. Germina: Revista de Literatura e Arte, [s. n.], v. 10, n. 39, mar. 2015.

PIGOZZI, Douglas. Os quadrinhos como fonte de informação para o estudo da realidade social: o pensamento anarquista e o autoritarismo em V de Vingança e Watchmen. 2013. Dissertação (Mestrado em Ciências da Comunicação) - Escola de Comunicações e Artes, Universidade de São Paulo, São Paulo, 2013. 
RAMOS, Rubem Borges Teixeira; DUMONT, Lígia Maria Moreira. Leitura e obtenção de conhecimento nas histórias em quadrinhos de super-heróis. In: ENCONTRO NACIONAL DE PESQUISA EM CIÊNCIA DA INFORMAÇÃO, 9., 2008, São Paulo. Anais... São Paulo: USP, 2008. p. 1-16.

SANTOS, Mariana Oliveira; GANZAROLLI, Maria Emilia. Histórias em quadrinhos: formando leitores. TransInformação, Campinas, v. 23, n. 1, p. 63-75, jan./abr. 2011.

SANTOS, Roberto Elísio; VERGUEIRO, Waldomiro. Histórias em quadrinhos no processo de aprendizado: da teoria à prática. EccoS: Revista Científica, São Paulo, n. 27, p. 81-95, jan./abr. 2012.

SILVA JÚNIOR, Hélio Yarzon; PEREIRA, Rodrigo; SOARES, Ana Paula. Relação entre os filmes do Marvel e o incentivo a leitura por meio das histórias em quadrinhos. In: CONGRESSO BRASILEIRO DE BIBLIOTECONOMIA, DOCUMENTO E CIÊNCIA DA INFORMAÇÃO, 25., 2013, Florianópolis. Anais... Florianópolis: Centrosul, 2013.

SILVA, Andréia Gonçalves; SILVA, Leonardo Gonçalves. O acesso à informação jurídica através de histórias em quadrinhos e cartilhas.

Informação \& Informação, Londrina, v. 17, n. 1, p. 166-183, jan./jun. 2012.

SILVA, Jane Quintiliano G. Gênero discursivo e tipo textual. Revista Scripta, Belo Horizonte, v. 2, n. 4, p. 87-106, 1999.

SILVA, Rafael Laytynher. A contribuição das histórias em quadrinhos de super-heróis para a formação de leitores críticos. Revista Anagrama, São Paulo, v. 5, n. 1, set./nov. 2011.

VERGUEIRO, Waldomiro. Histórias em quadrinhos e serviços de informação: um relacionamento em fase de definição. DataGramaZero, Rio de Janeiro, v. 6, n. 2, abr. 2005.

VERGUEIRO, Waldomiro. Histórias em quadrinhos. In: CAMPELLO, Bernadete; CALDEIRA, Paulo da Terra; MACEDO, Vera Amália Amarante (Org.). Formas e expressões do conhecimento: introdução às fontes de informação. Belo Horizonte: Escola de Biblioteconomia da UFMG, 1998. p. 117-149.

\section{Title}

Appropriation and the uses of comics in information science literature 


\section{Abstract}

Introduction: This article realizes the bibliographic mapping in the studies of Information Science, to demonstrate the development of comics in this area.

Objective: Mapping studies about comics made in Information Science, showing their uses and appropriations in the dissemination's process of the collected results in this research.

Methodology: Bibliographical research with qualitative-quantitative approach.

Results: The comics are subject of research in Information Science from the perspective of the dissemination and interpretation of informatiom. Its use helps in the learning of the users and scholars shows its benefits. The studies demonstrate that the comics provide a mental effort because the visuals also allow learning. Studies also show that they can be used for research, where are showed the knowledge acquired in reading of comics, in other words, the knowledge without scientific basis.

Conclusions: Concludes that some studies of Information Science determine which purposes the comics are appropriated by users.

Keywords: Comics. Bibliographic mapping. Information science.

\section{Titulo}

Apropiaciónes y usos de las tiras cómicas en la literatura de Ciencia de la Información

\section{Resumen}

Introducción: Este artículo realiza un mapeamento bibliográfico a partir de los estudios en Ciencia de la Información, para demostrar el desarrollo de las tiras cômicas en esta area.

Objetivo: Mapear los estudios acerca de las tiras cômicas hechos por la Ciencia de la Información, indicando sus usos y las apropriaciones en el proceso de diseminación de los resultados colectados en esta pesquisa.

Metodología: Pesquisa bibliográfica con abordaje cualitativa y cuantitativa.

Resultados: Las tiras cômicas son tema de pesquisa en la Ciencia de la Información desde la perspectiva de la diseminación y interpretación de la información. Su uso auxilia en la aprendizaje de los usuarios y los estudiosos evidencian sus benefícios. Los estudios destacan que las tiras comicas propician esfuerzo mental, porque los recursos visuales también permiten aprendizaje. Los estudios tambien indican que ellas pueden ser utilizadas para la pesquisa, en que son salientados los conocimientos adquiridos por la lectura de tiras cômicas, o sea, el conocimiento sin fundamentación científica.

Conclusión: alguns estudios de la Ciencia de la Información determinan con cuales finalidades las tiras cômicas son apropriadas por los usuários.

Palabras-clave: Tiras cômicas. Mapeamento bibliográfico. Ciencia de la Información.

Recebido: 15.10 .2015

Aceito: 16.04 .2016

Inf. Inf., Londrina, v. 21, n. 1, p. 56 - 79, jan./abr. 2016. 